\title{
The developing role of occupational therapists in school-based practice: experiences from collaborative action research in Pakistan.
}

\section{Short title: Developing school-based occupational therapy in Pakistan.}

\section{Author list:}

1. Debbie Kramer-Roy, European MSc in Occupational Therapy, Amsterdam University of Applied Sciences, Amsterdam, The Netherlands

2. Denise Hashim, Department of Occupational Therapy, Dow University of Health Sciences, Karachi, Pakistan

3. Nighat Tahir, Department of Occupational Therapy, Dow University of Health Sciences, Karachi, Pakistan

4. Areeba Khan, Department of Occupational Therapy, Dow University of Health Sciences, Karachi, Pakistan

5. Asma Khalid, Department of Occupational Therapy, Dow University of Health Sciences, Karachi, Pakistan

6. Nasira Faiz, The AMI School, Karachi, Pakistan

7. Rabeea Minai, The AMI School, Karachi, Pakistan

8. Samreen Jawaid, The AMI School, Karachi, Pakistan

9. Shaheen Khan, The AMI School, Karachi, Pakistan

10. Rakhshanda Rashid, The AMI School, Karachi, Pakistan

11. Tai Frater, Brunel University London, UK

Corresponding author: Dr Debbie Kramer-Roy, Director Education of the European Master of Science in Occupational Therapy, Amsterdam University of Applied Sciences, Tafelbergweg 51, 1105 BD Amsterdam.

Email: d.e.kramer-roy@hva.nl

\section{Abstract:}

Introduction: Occupational therapists around the world increasingly seek to support the participation of children with disabilities and special educational needs in mainstream education. Contemporary school-based occupational therapy practice is progressing from an individual, impairment focus towards collaborative, universal interventions at class and whole school level. Participation-focussed practice and collaboration is particularly important, but uncommon, in lowresource contexts such as Pakistan.

Methods: This article reports on collaborative action research that developed the role of Occupational Therapy in Inclusive Education in Karachi, Pakistan. A research team consisting of occupational therapists and teachers worked with five local primary schools, using the action research cycles of plan-implement-observe-reflect to develop practical strategies, materials and inclusive lesson plans to facilitate the participation of all children in all school-based occupations.

Findings: Support from school management and interdisciplinary collaboration were crucial for implementing change. In addition, strategies like inclusive lesson planning were found to benefit all 
children in class. Collaborative action research led to increased professional confidence in the teachers and occupational therapists and skill development through developing a resource guide, running workshops and presenting at (inter)national conferences.

Conclusion: Collaborative action research was an effective means to develop the occupational therapy role in inclusive education practices in Pakistan, develop culturally appropriate educational resources and upskill local therapists and teachers.

\section{Key Words:}

- Inclusive Education

- School-Based Occupational Therapy

- Collaborative Action Research

- Children with Special Needs

- International Development

\section{Background and Introduction:}

Education in Pakistan:

In Pakistan access to education is limited, with a net primary school attendance ratio of $76 \%$ for boys and $60 \%$ for girls (Unicef, 2017). It is rare to see children with obvious disabilities in mainstream schools and there are few special schools. Hameed and Manzoor (2016) estimate that $95 \%$ of disabled children in Pakistan are out of school. It is unclear how many children with invisible and/or unidentified special needs are in school. Anecdotal evidence suggests that some schools permit children with special needs to study if their parents pay for a teaching assistant.

Surprisingly, legislation to ensure free compulsory education is in place in several provinces in Pakistan, for example the Sindh Right of Children to Free Compulsory Education Act (Provincial Assembly of Sindh, 2013) explicitly states that this applies to children with disabilities and special needs. However, in the education sector awareness and implementation of this right is extremely limited.

\section{Inclusive Education:}

The Salamanca Statement on Special Needs Education (1994) describes Inclusive Education as a process of strengthening the capacity of education systems to include all children in their communities. It also is an effective means to reduce discriminatory attitudes, contribute to an inclusive society and achieve Education for All (UNESCO, 1994; United Nations, 1989).

The United Nations Committee on the Rights of Disabled Persons (2016) differentiates inclusion from exclusion, segregation and integration:

- Exclusion occurs when students are denied access to education in any form.

- Segregation occurs when the education of students with disabilities is provided in separate environments designed or used to respond to impairments, in isolation from students without disabilities

- Integration is a process of placing students with disabilities in existing mainstream schools, as long as they can adjust to the standardised requirements

- Inclusion involves a process of systemic reform, embodying changes and modifications in content, teaching methods, approaches, structures and strategies in education to overcome 
barriers, in order to provide all students of the relevant age range with an equitable and participatory learning experience.

This differentiation was crucial in this project and the team used the following image for their own conceptualisation as well as in networking and dissemination:

\section{Figure 1: Defining Inclusion}

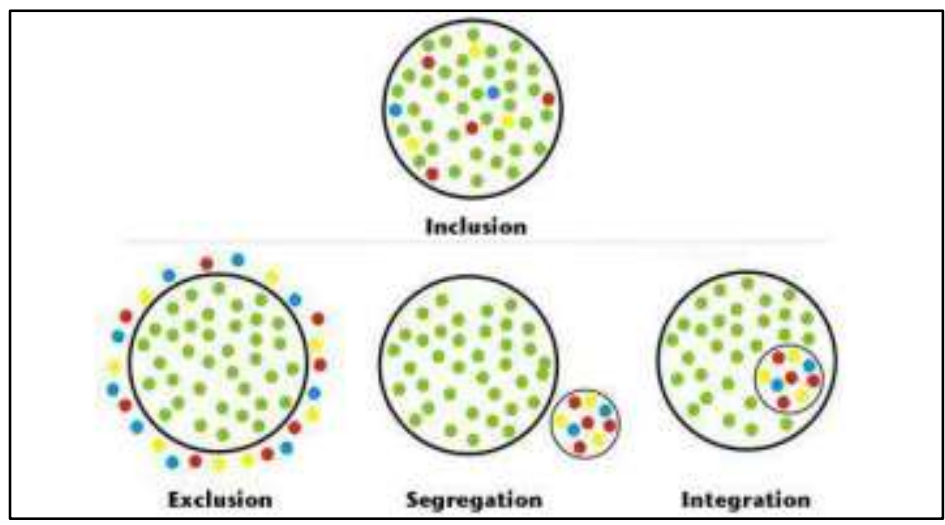

Source: unable to identify original source, used on many internet sites, see https://www.thinkinclusive.us/inclusion-exclusion-segregation-integration-different/

\section{Occupational Therapy in Pakistan:}

Occupational Therapy is a small profession, with only 400 occupational therapists working in Pakistan (World Federation of Occupational Therapists, WFOT, 2018), with a population of around 200 million. Opportunities for occupational therapy-specific continued professional development are very limited within Pakistan. Both clinical practice and education are mostly based on the medical model of disability, with a focus on individual impairment-based approaches.

\section{Literature review:}

This paper focuses on the aspect of inter-professional collaboration, which is instrumental in developing inclusive education. A literature search was conducted in CINAHL and ERIC databases and Google Scholar, and reference lists of articles were manually searched for further articles. Search terms were used in the following combinations:

\section{TABLE 1 - Search terms used in CINAHL, ERIC and Google Scholar.}

Inclusive education
Inclusion
Special needs
School-based
Mainstream

Occupational therap*
Professional*
Inter-professional
Stakeholder

Collaborat* Support Facilitate*

To make Education for All (UNESCO, 1990) inclusive, collaboration between all stakeholders, i.e. teachers with knowledgeable professionals, within and between schools, and between schools and communities, is essential (Ainscow and Miles, 2008). The focus must be on developing education systems within which teachers feel supported as well as challenged in their responsibility to explore more effective ways of facilitating the learning of all students (Ainscow and Miles, 2008). 
School leadership and organizational culture play a significant role in achieving an inclusive education system and they must ensure that the methodology for developing inclusive practices take account of the social processes of learning within particular contexts (Ainscow and Sandill, 2010). This requires a group of stakeholders to look for a common agenda to guide their discussions of practice and a series of struggles to establish ways of working that support inclusion (Ainscow and Sandill, 2010). This is illustrated by an Appreciative Inquiry study that sought to facilitate stakeholders including parents, educators, occupational therapists and programme administrators to develop a common understanding of "School Based Occupational Therapy". Participants indicated that they "learned most from hearing the successes and challenges from different perspectives.... The importance of collaboration and communication was emphasized and makes me think about how I personally can do a better job within my own role" (Villeneuve and Shulha 2012, p299).

Kennedy and Stewart (2011) found that collaboration between occupational therapists and teachers lead to better student success and performance in the areas of learning, social experiences, play and academic success. However, Suter et al, (2009) identified barriers such as lack of time, unrealistic expectations, lack of understanding of the collaborative approach and occupational therapists' discomfort in the classroom. To overcome these barriers, communication and role understanding were identified as core competencies, with additional important aspects identified as ethical practice, such as respect for each other's professional roles and skills, client participation in service planning, sharing professional knowledge, mentoring, joint assessment and reflection (Suter et al, 2009). Herbert et al (2007) identified similar characteristics of collaborative practice, but added factors influencing professionals to develop this collaborative ability. These included social norms, role models, and positive exposure to collaborative environments and negative exposure to noncollaborative environments. Harmful supervision relationships, experience of working in professional 'silos' and a devaluing of certain professions were also significant. The main challenges related to issues around power and territory, and the time needed to communicate in a collaborative model (Herbert et al, 2007).

In their scoping review Wintle et al (2017) identified a number of similar tensions arising from collaboration between occupational therapists and teachers at professional socialisation, person and environment level. They point out that strategies such as basing occupational therapists in schools rather than visiting sporadically have implications for funding, thus requiring policy changes at national or local level. Wintle et al (2017) conclude that "whatever steps are taken to address the tensions identified..., they should be done using participatory approaches that engage both professions to better ensure their commitment and a shared vision of what it means for occupational therapists and teachers to collaborate with each other" (p15). This resonates well with the collaborative action research approach taken in the current study.

The World Federation of Occupational Therapists (WFOT) Position Statement on Occupational Therapy Services in School-Based Practice for Children and Youth (2016) supports international policies on Inclusive Education and, in line with the above findings, emphasises that occupational therapists need to "provide collaborative support to enable occupation and to remove or reduce barriers to participation of all students, particularly those with special educational needs". To facilitate this, it promotes a tiered approach to intervention, in line with approaches such as Response to Intervention (Ardoin et al, 2005) and Partnering for Change (Missiuna et al, 2012). The position paper (WFOT, 2016) identifies the three tier or levels as follows: 
- At the Primary level of "Universal Design for Learning" the whole school / classroom environment and activities are designed keeping in mind all learners, e.g. inclusive lesson planning.

- At the Secondary level the focus is on "Differentiation", for example adapting materials or activities for an individual child so they can participate in the same activities as their peers within the classroom.

- At the Tertiary level the focus is on "Accommodation and Individual Intervention", which includes therapy outside class and providing individual activities or strategies within or outside the classroom.

It is evident that effective collaboration between professionals and parents is essential for developing inclusive education. The factors that influence successful collaboration are complex and vary depending on the context. As school-based roles have started to emerge, the WFOT statement (2016) challenges Occupational Therapists to work collaboratively with school staff, other professionals and parents. For example, in Partnering for Change (P4C) (Missiuna et al, 2017), a research based, well established model, Canadian occupational therapists work collaboratively with educators in classrooms to observe, identify, and support children. The whole school is viewed as the client and the occupational therapist's role is to work proactively with educators to collaboratively design physical, social, and learning environments that facilitate the successful participation of all students. Missiuna et al (2017) conclude that children can be identified and supported without the need for standardized assessment, formal referrals, and waitlists, leading to a more efficient and cost-effective service.

\section{Purpose:}

In view of the fact that the majority of Pakistani children with special needs are either out of school, or not included and supported effectively to participate in school occupations, a 3-year collaborative action research project was conducted with the aim to develop the role of Occupational Therapy in Inclusive Education. This approach to research was chosen as it was anticipated that interprofessional collaboration would be crucial to achieve this aim.

Considering the unique Pakistani context, it was decided not to apply or pilot an existing model of school-based occupational therapy, but rather to use the reflective action research cycles (see below) to develop a contextually relevant approach, building on literature on inclusive education and occupation-based approaches to intervention.

The overall focus was on developing Primary and Secondary level interventions, as Tertiary level interventions were not a new concept to the occupational therapists and not a priority, in view of the WFOT (2016) position paper. Where Tertiary level interventions were needed, these were carried out within the classroom or playground setting with peers wherever possible, to ensure optimal inclusion. The levels are indicated in brackets with the examples given in the findings below.

\section{Methodology:}

This three-year (2015-2018) action research project was funded by the Knowledge Economy Partnership (KEP) funding from the British Council and the Higher Education Commission of Pakistan. In line with the funding agency's guidelines, three partner institutions conducted the research: the Occupational Therapy divisions at Brunel University London (UK) and Dow University of Health Sciences University (Pakistan), and a non-university partner, in this case The AMI School, (Pakistan). 
Ethical approval was granted by the Research Ethics Committee of the Department of Clinical Sciences of Brunel University London, as well as the Institutional Review Board of Dow University of Health Sciences. Signed consent was provided by the research team members, for the use of data collected through pre- and post-project questionnaires and focus groups, and through Reflective Logs. The ethical review committees agreed to an "opt-out" procedure, by which parents were able to withdraw their children from the project, because the research activities were deemed to be part of the educational activities offered by the school for the purpose of school improvement. No parents chose to withdraw their child from the project. While the names of the participating schools were anonymised, The AMI School as the partner institution opted to be recognised for their role in conducting the project.

\section{Figure 2: The Project Phases}

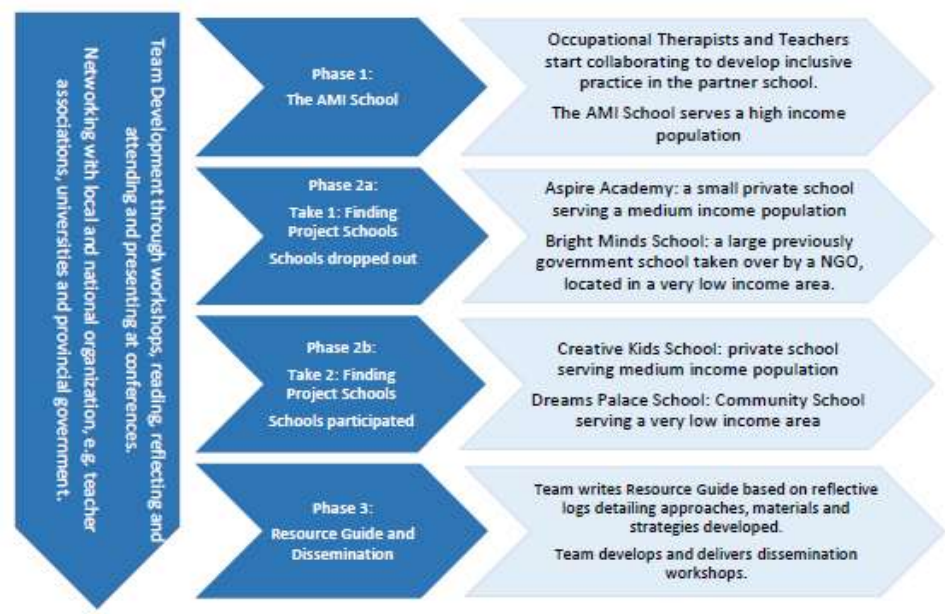

The AMI School already identified itself as an inclusive school, but realised it needed to develop this approach further. In total five schools from a range of socio-economic backgrounds were involved in the project to ensure the findings would reflect the reality of all Pakistani schools. The UK team leaders visited Pakistan for two visits each year, during which Pakistani team members received training on key concepts such as inclusive education, (action) research and occupation-based approaches to intervention, as well as reflecting and planning together. In addition, the Pakistani team members visited Europe in groups to observe and critically reflect on examples of school-based occupational therapy in another context, and to present the project at conferences.

\section{Choice of research method:}

Action Research was chosen in view of the overall purpose of the project which was to develop the role of occupational therapy in inclusive education. This approach actively engages all co-researchers in a research process that seeks to address a situation that is problematic for them in order to improve it. Action Research involves an iterative cyclical process of observing, reflecting, planning and acting, "providing a way of working which links theory and practice" (Kemmis et al, 2004, p1). The iterative nature of the process means that data arising from one action cycle is analysed in the observing and reflecting phases to plan for the next action cycle. This way the analysis serves to propel the action research cycles forwards, encouraging the team to ask new questions, debate their diverse views and make sense of the overall development of their approach to inclusive education (Cahill, 2010). In addition, the process consists of multiple cycles at different levels (e.g. the three phases of the project, the process within each school, and the process around the challenge in each classroom or child) and interlinking with each other (please see Figure 3 for an overview of the project phases). Messiou (2018) argues that what is distinctive in collaborative action research is the 
coming together of different stakeholders (as in this case occupational therapists and teachers) who take on the role of co-researchers and collaborate to understand a social process.

\section{Figure 3: The Action Research Process}

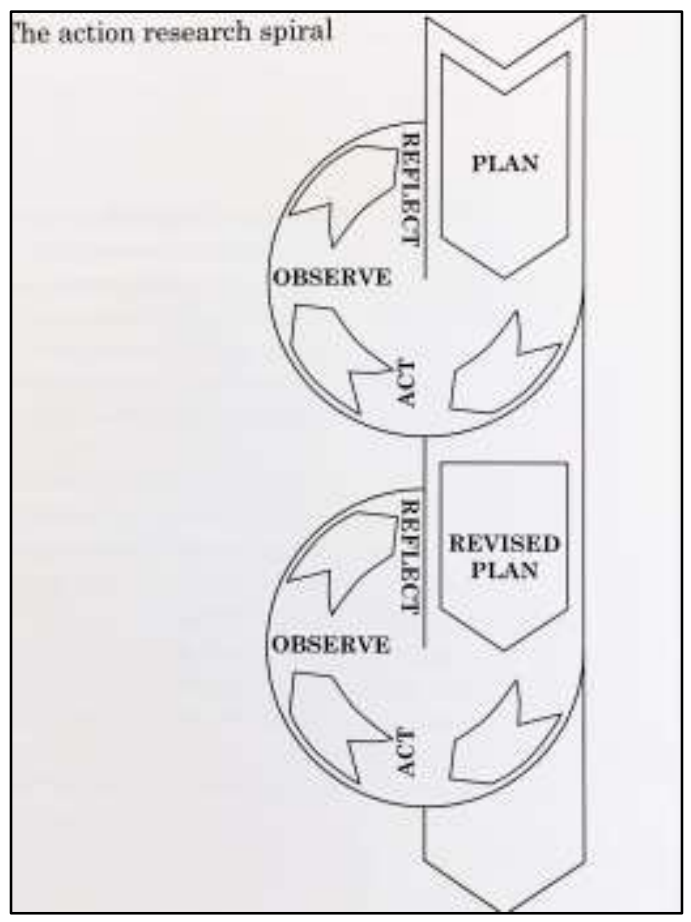

Source: Kemmis et al (2004)

Trentham and Cockburn (2015) point out that (participatory) action research is "consistent with the values of occupational therapy and occupational justice" (p440) and that co-researchers develop valuable life-skills, such as working as a team, planning and decision-making. This was important in view of the very limited opportunities for professional development and capacity building of occupational therapist and teachers in Pakistan.

Action Research proved very effective for developing a contextually relevant approach to inclusive education and critical refection on this process is presented in detail elsewhere (Sajid et al, in preparation).

\section{Methods:}

The project had three main phases or action research cycles, during which the Pakistan-based coresearchers worked together for one day per week (see figure 2). Within each of these big cycles, there were multiple smaller cycles for each challenge identified at child, classroom or school level, each of which in turn informed later cycles.

In phase 1 the occupational therapists visited the AMI School to work with the teachers in the school and classrooms; in phase 2 the team split into two mixed teams (occupational therapists and teachers), with each team visiting two new schools to work in the same way with the teachers in those schools; in phase 3 the research team focused on dissemination through workshops and conferences, and on writing the Resource Guide (Kramer-Roy, 2018). The participating schools were from different socio-economic backgrounds to be representative of Pakistani schools. Two schools dropped out, after which two further schools were recruited. The experiences from the first two 
schools were very important for the team to reflect on as they highlighted the challenges faced by these schools, such as lack of institutional support and less buy-in from teachers, thus forming a significant action research cycle.

In each school an initial situational analysis was carried out, to describe to what extent children with special needs were included already and how the physical and social environment affected their learning. Challenges identified formed the starting point for the team members and Reflective Log formats were developed to structure and record the ensuing action research cycles week by week, i.e. a Classroom Observation Log (see appendix), a Resource Development Log (see appendix) and a general Reflective Log. Team members emailed all logs to the principal investigator, who provided feedback on the action research process, in time for the next week's visit.

The data consists of all completed logs and reports of workshops and discussions held during project visits. Additional data, collected through pre- and post-project individual questionnaires and separate focus groups of the occupational therapists and teachers on the team, have been thematically analysed separately and will be published in due course.

\section{Data analysis:}

In Action Research data analysis is an iterative process that is encompassed in the multiple cycles of planning, action, observation and reflection, in which "data generated in each cycle of activity are analysed and reflected on ... and inform the next cycle of activity" (Francis (2013, p158).

Accordingly, the research team evaluated the outcomes of the action research through the ongoing discussion of the cycles recorded in their reflective logs, through review meetings during visits by the UK based team members, and finally a planning workshop to prepare for this publication. The data collected were also used to produce a Resource Guide in English (available on the project website www.otiepakistan.pk) and Urdu (not yet finalised), to facilitate dissemination throughout Pakistan (Kramer-Roy, 2018). The Resource Guide introduces key concepts, provides practical strategies for inclusion (divided into a section focusing on preparing for inclusion at school and classroom level, and a section on responding to specific challenges) and sections with additional information and resources, both local and international. Importantly the Resource Guide emphasises the process by which to achieve inclusion, as well as giving practical examples of how this worked in specific situations. Examples given in this article have been taken from the Resource Guide.

\section{Quality in Action Research:}

Validity and rigour in Action Research are defined in line with its unique approach which differs from other qualitative research. The quality criteria proposed by Herr and Anderson (2005) and how they were met in this study, will be described in the Discussion section below.

\section{Findings - The importance of collaboration:}

This section is structured according to the themes pertaining to inter-professional collaboration, arising from the ongoing and summative analysis and evaluation process described above.

In their reflections on the most significant outcomes of the project, the research team emphasised the effects of collaboration between various people at all levels in and beyond the schools, which enabled a process of whole school improvement. As collaboration between health and education professionals is rare in Pakistan, the team discovered and recognised its significance early in the project and reflected on this aspect throughout the action research cycles. 


\section{Collaboration with the school leadership and management}

Across the five participating schools, the willingness and cooperation of the school management to work towards inclusive education proved to be the key to starting and continuing the process. The first step was their acceptance of the school's responsibility to become inclusive. This was clearly the case in the partner school, The AMI School, where the owners of the school were also providing the day to day leadership. Without their visionary leadership and commitment to releasing the team members from their teaching duties for one day per week, it would have been impossible to complete the project. Of the two schools who dropped out, one understood this responsibility well, but found that they faced more pressing social issues affecting all children in the school and were unable to work on inclusive education at the same time. In the other school the principal (visionary and day to day leadership) was committed to the project, but when she left the school due to illhealth, the owner (higher administrative management) was unwilling to continue with the project. Of the two remaining participating schools, it was challenging to engage the higher management in one, causing the principal limited freedom to release teachers to collaborate with the team. Consequently, less changes were achieved in this school than in the final school where the management openly welcomed the team to support their principal and teachers to include all children in their classes.

An example of school management at the AMI School supporting the concept of removing barriers to learning for all children, is the addition of the heading "inclusive activity" in the lesson planning format for kindergarten teachers. This prompted teachers to remain aware of all children's participation in all lessons (Primary Level) and to seek support from their colleagues on the research team if needed, to achieve this. Another example is a change in timetabling to build in regular 15 minutes breaks instead of one break of 25 minutes during the school day, providing all children with regular breaks, thus removing a structural barrier for children with a heightened need for movement (Primary Level).

In Dreams Palace School strategies to support a classroom with older children to better follow the classroom rules and instructions included daily physical activities and lesson plans that provided a combination of activities including recap, brainstorming, introduction through concrete material, hands on tasks in groups, recording and finally concluding through games and activities. To enable this, desks were rearranged to form groups. Initially only the science teacher implemented this, but after discussion with the school management, the plan was implemented by all teachers, for this and other classes, leading to improvement in children's behaviour and engagement in lessons across the school (Primary Level).

\section{Teachers and occupational therapists learning through collaboration}

The team members needed time to adjust to the classroom-based collaboration as they were unsure what to expect from each other. Teachers initially felt intimidated by an occupational therapist observing their class. At the same time, the occupational therapists were used to giving professional advice and some initially forgot to take off their white coat (both literally and figuratively) in the school. It took some time for both professions to discover and appreciate the unique professional knowledge and skills in each other. The occupational therapists realised how challenging it is to teach a large class for a whole day, keeping all engaged in learning despite varied learning needs. At the same time, the teachers discovered how the specialist knowledge about child development, learning and activity analysis of the occupational therapists could help them understand and teach their students better. 
Once mutual respect was established, collaboration improved. The teachers gained confidence in supporting individual children (Secondary and Tertiary Level) and developing inclusive lesson plans and strategies for the whole class (Primary Level), to the extent that they were able to disseminate these new approaches to their colleagues within the school who were not part of the research team. The collaboration was further strengthened when the team split into two mixed teams of teachers and occupational therapists (see methods section and figure 2 above) to work with the new schools. This required them to identify as one research team combining their professional skills, in order to support and facilitate the teaching staff in the new schools to become more inclusive in their teaching.

\section{The benefits of inter-professional collaboration to the students}

The teachers reflected that before the project they focused mostly on the content when planning their lessons, rather than on the children they were teaching. Collaborating with the occupational therapists enabled them to recognise the learning needs of one or more children in class, causing them to consider learning and teaching methods more carefully. They soon observed that frequently other children in class benefited from the improved teaching methods, materials or classroom strategies too.

For example, strategies developed for 5 -year old Ayesha (pseudonym) benefited her whole class at Creative Kids School. Ayesha had autism, leading to difficulty attending to tasks and following instructions, and running around frequently. The occupational therapist taught the teacher to use individual (Tertiary Level) and whole-class (Primary Level) proprioceptive activities, for example jumping in and out of circles, tug of war and hopping races. To help with lining up for transitions, number tags were put on the back and hand of all children to understand where to stand. Other strategies included visual cue cards (Secondary Level) for instructions for the whole class, and reward stickers on Ayesha's hand rather than a chart (Secondary Level). Implementing these strategies at class level motivated both Ayesha and her classmates. The increase in proprioceptive input led to less distraction and pacing in class, longer calm sitting times in class and at lunch, and the ability to focus longer for Ayesha (Tertiary Level). She seemed proud of herself and more socially included. Other children were motivated to participate with her, followed instructions more easily with visual cues, and enjoyed getting reward stickers (Primary Level).

An example of a whole-class approach (Primary Level) was for Class 2 children in Bright Minds School, where the classroom was not spacious enough for students and teacher to move about during activities. The seating arrangement was set up in three rows and the children's bags were kept on their chairs, reducing space for them to sit and leading to restlessness. With doors open due to the heat, noise from outside made it difficult for the students to hear the teacher's instructions clearly. By re-arranging the desks in small table-groups, providing space for schoolbags at the back of class, coordinating activities between classes and corridors, and moving the board, the students were able to work collaboratively on their work with better attention to task.

\section{Collaboration with parents}

Parents also benefited from the project at individual and at group level. The collaboration with the occupational therapists enabled the teachers in all schools to understand the nature of their students' learning needs better, and together they were able to decide how parents might be able to support the child better at home. This ensured clearer instructions for individual activities, behavioural strategies and homework support (Primary Level). 
In addition, parent workshops were offered to all parents in the schools on topics such as supporting homework and understanding bullying. In the AMI School some progress was made towards the parent body supporting the ethos and approaches to inclusive education at the school level. For example, during one workshop, parents themselves offered each other approaches they had used successfully, to support their child's learning (Primary Level). Similarly, following a discussion in a workshop on homework strategies for parents in Creative Kids School, the parents formed an evening group to discuss homework and to explore ways to support their children in their homework (Primary Level).

\section{Impact of the project on the Occupational Therapists}

As described above, the occupational therapists on the team were initially challenged by this new way of working with the teachers. Therefore, their intensive professional development process resulting from working collaboratively with the teachers and UK based team members will be described in more detail here.

The developing role of occupational therapy in inclusive education in Pakistan

The occupational therapists on the team noted that occupational therapy in Pakistan is operating mainly from an individual, impairment-focused perspective, often providing authoritative expert advice, i.e. focusing mostly on the Tertiary level of intervention. As this is not in line with the international guidelines on Inclusive Education, the action research cycles included workshops on current trends in occupational therapy internationally, including rights-based approaches based on occupational justice theory, as well as participatory and emancipatory approaches to research. In addition, the team was introduced to the Person-Environment-Occupation (PEO) Model of Occupational Therapy (Law et al, 1996), which facilitates the analysis of occupational performance difficulties keeping in mind not only the child's impairment, but also their strengths and preferences (person), environmental factors that facilitate or hinder participation (environment), and the suitability of the task for the child (occupation). The PEO model facilitated them to broaden their perspective and role in addressing classroom challenges (Primary and Secondary Level), and to understand how they could collaborate more closely with the teachers to consider all factors that impact children's inclusion (Primary Level). The Classroom Observation Log and Resource Development Log facilitated problem-solving with the teachers about the classroom environment, for example considering where the child is positioned in class and reducing visual and/or auditory distractions (adjusting the environment, Secondary Level), and supporting the teacher to prepare inclusive lesson plans to teach the same content in a way that makes it more easily accessible for the student(s) with special needs (adjusting the occupation, Primary and/or Secondary Level).

\section{Enhanced clinical reasoning}

The occupational therapists reported that their clinical reasoning had improved in the project schools as well as their clinics, as they now use the PEO model to structure their individual assessment, broadening their view from a focus on impairment as the main cause of restrictions in functioning (Tertiary Level), to considering how the environment and the way tasks are expected to be carried out might impact the child's ability to participate in self-care or play activities (Secondary Level).

Recognising the levels of intervention:

The occupational therapists on the team reflected on how their new practice reflected the three levels of intervention supported by the WFOT (2016) Position Paper, reasoning that in school-based 
occupational therapy, there should be a move from Tertiary Level intervention towards Primary and Secondary Levels of intervention. They further reasoned that by using their occupational therapy skills, inclusive education does not need to be expensive as occupational therapists are skilled in using and modifying everyday items to promote learning (Secondary Level) and are able to advise teachers regarding elimination of barriers in the environment (Primary Level).

\section{Discussion:}

In this collaborative action research project, the team experienced many of the processes and challenges that the literature review had shown to be important in other contexts. This section discusses these challenges, and the approaches to overcoming them, in light of the literature. Wintle et al's (2017) conclusion that participatory approaches need to be used to engage both professions in this process to ensure that the vision and approaches successfully address the specific local challenges and opportunities, were made evident in this project.

The initial barrier of lack of understanding and respect of each other's role (Herbert et al, 2007) was partly due to the very limited contact the teachers and occupational therapists had experienced with each other's professions before, as the 'professional silos' (Suter et al, 2009) are particularly stark in Pakistan. This led to discomfort in both professions when the occupational therapists started spending time in the classrooms (Kennedy and Stewart, 2011).

In this study, issues of power and territory (Herbert et al, 2007) were evident in both professions. Within each school, these issues were not only contributed to by the teachers, but also by their principals and managers, particularly in the schools that later dropped out. The participatory nature of the project facilitated intensive collaboration and communication in a similar way as Villeneuve and Shulha's appreciative inquiry study (2012). This did not only happen through the school-based action research cycles, but also through the big cycles in which capacity building workshops, the critical review of relevant literature individually and together, and joint reflection and planning were undertaken. These joint activities supported the process of the research team starting to develop their common agenda and to guide their discussions of practice in order to improve it, which Ainscow and Sandill (2010) emphasise as crucial to developing inclusive practises. As the respect for each other's professional roles and skills - identified by Suter et al (2009) as a core prerequisite for overcoming barriers to collaboration - increased, the teachers in all schools felt more and more supported by the occupational therapists and therefore more able to take on the responsibility for including children with special needs in their classes (Ainscow and Miles, 2008).

In line with previous research in other countries such as Partnering for Change (Missiuna at al, 2012), the research team found that collaboration with each other, the school leadership and the parents was essential for creating more inclusive school environments. This was as evident in the schools where this was successful, as where it was challenging. The positive exposure to this collaborative environment, described by Herbert et al (2007) as an essential factor for professionals to develop collaborative ability, was the strongest in the AMI School. The reasons for this were that they were involved throughout the whole three years of the project, while the other schools only had this exposure for one academic year, and that they had more exposure to the capacity building activities. Their continued activities to support all colleagues in their own school who were not directly involved in the project, and to facilitate workshops to introduce the approach and Resource Guide to other schools in Karachi, more than a year after the end of the project, demonstrate their sustained vision and commitment to promoting inclusive education in Pakistan. This demonstrates the need 
for longer and consistent exposure, which is difficult to accomplish in a poorly resourced education system.

\section{The quality of the Action Research process:}

Herr and Anderson's (2005) quality criteria for Action Research were used to evaluate the processes and outcomes of this project. They propose the following quality criteria related to goals of Action Research: the generation of new knowledge (dialogic and process validity), the achievement of action-oriented outcomes (outcome validity), the education of both researcher(s) and participants (catalytic validity), results that are relevant to the local setting (democratic validity), and a sound and appropriate research methodology (process validity).

These criteria were met in the following ways:

First of all, new knowledge was generated through the collaborative process recorded in the various reflective logs, and structured and synthesised to produce the Resource Guide. Secondly, actionoriented outcomes include the inclusive practice in the participating schools, collaboration between occupational therapists and teachers, dissemination workshops for new schools and teachers, and the Resource Guide, all of which have continued since the end of the project. However, it remains to be seen what the broader impact will be, and to this end feedback is requested from those who access the resources. Thirdly, education of both researcher and participants is evident in the significant professional development of the team members (to be published in more detail elsewhere), and the teachers and parents in the participating schools. This is evident in continued initiatives taken by the teachers at the AMI School to support their colleagues to include children with special needs in their classrooms. Similarly, curriculum content has been added to the BSc in Occupational Therapy to ensure current students are equipped to support inclusive education when they graduate. Fourthly, the results are relevant to the local setting as planning, action, observation and reflection was carried out in the local context by researchers from that context. Furthermore, the Resource Guide and workshops continue to be in demand by other schools and professions working towards inclusive education. Finally, a sound and appropriate research methodology was used and developed in response to the team members' experience in each cycle (e.g. the stages in the resource development log). These outcomes were facilitated through the use of participatory approaches to develop the role of occupational therapy in inclusive education in Pakistan, including to address challenges and tensions arising in the process, in line with Wintle et al's (2017) recommendations.

\section{Limitations of the project:}

Despite the success of this project and it meeting Herr and Anderson's quality criteria (2005) to a great extent, important challenges remain. The limited professional education and reasoning, as well as lack of research experience of the Pakistani team members meant that they needed a high level of training, support and coaching. This benefited them greatly and enabled them to continue using the approach beyond the end of project. However, during a review visit one year later, it was evident that the teachers in the additional project schools who had had a shorter and less intensive exposure, had not been able to sustain the approach to the same extent. This raises concerns over implementation by schools and teachers who acquire the Resource Guide, especially if they do not have an opportunity to attend an introductory workshop. More clarity about this will be gained once enough responses to the automatically generated online questionnaire, which they receive four months after requesting or downloading the Resource Guide, will be received. Limited use of social 
media for professional networking, and the delay in funding of the Urdu translation is slowing down the dissemination of the Resource Guide.

An additional major barrier to dissemination of the findings and the Resource Guide to other schools in Pakistan is limited political will and funding to implement inclusive policies already in place (Provincial Assembly of Sindh, 2013). Keeping in mind the high percentage of out-of-school children, particularly those with special needs, the capacity building of the workforce is urgent. With policies promising free compulsory education for all already in place, a well-prepared workforce is essential for making this a reality, and the findings of this study have been presented to government agencies responsible for teacher education, with the offer to contribute to teacher training.

In terms of research methodology, Action Research was appropriate in view of its collaborative and emergent nature, which supported the development of a contextually relevant approach to occupational therapy-supported inclusive education. However, it is acknowledged that working together closely over a long period (a strength of this methodology) bears the risk of subjectivity or bias. To limit this, the Principal Investigator herself reflected on her role and influence on the research activities, as well as encouraging the research team to do the same. The use of the reflective logs was helpful in this process, as it guided the team members to continuously 'step back' to observe and reflect on the results of the actions they planned and carried out in each action research cycle. The Principal Investigator provided feedback on all reflective logs written by the team members, focusing on the quality and effectiveness of the research process, rather than the content (such as the actual strategies and activities carried out), so as not to direct or control the outcomes of the project.

Similarly, the data collected through an Action Research process, and its ongoing analysis, is less structured and often more voluminous compared to other methods, such as interviews or surveys. A strength of this is that data is analysed on an ongoing basis at the Reflection stages of the action research cycles, so that subsequent cycles can build on it. However, a challenge is to then conduct an overall data analysis at the end of the process. In line with the collaborative nature of this study, this was done through interactive team workshops. As this is a less precise method of analysis, the additional data from individual pre- and post-project online questionnaires were analysed using a more conventional thematic analysis approach and will be published elsewhere; these have served as a way of triangulating the data.

\section{Conclusion:}

The collaborative nature of this study enabled occupational therapists to explore and implement new practices in partnership with teachers to develop approaches to occupational therapysupported inclusive education, in line with the WFOT position statement (2016). By following the Action Research cycles together, the occupational therapists developed a deeper understanding of the challenges of teaching a class of students with different abilities and needs, while the teachers developed their understanding of how children's special needs affected their functioning and participation in class. This enabled them to develop strategies to address barriers in the school environment and routines, and approaches to supporting individual children and whole classes to access school-based activities optimally. In addition, the occupational therapists reported that the professional development gained from the research process impacted on their clinical practice in other settings too. Finally, it became evident that interprofessional collaboration is not only possible in the Pakistani context, but crucial for making schools more inclusive. 


\section{Key Findings}

1. Action Research facilitated interprofessional collaboration, enabling development of inclusive strategies, materials and lesson plans

2. International guidelines on school, classroom and individual levels of intervention informed contextually appropriate approaches

\section{What this study has added:}

Occupational therapists are well-placed to use collaborative action research as a strategy for capacity building and empowerment, resulting in sustainable contextual solutions to include children with special needs in mainstream schools.

\section{Acknowledgments:}

The authors would like to acknowledge the members of the Advisory Group for their valuable guidance: Prof Susan Buckingham, Prof Nicola Madge, Dr Meriel Norris, Dr Cherry Kilbride Dr Nicola Ansell, and Dr Bella Vivat.

\section{Research Ethics:}

Ethical approval was granted by the Research Ethics Committee of the Department of Clinical Sciences of Brunel University London (Ref: 14/10/STF/23), as well as the Institutional Review Board of Dow University of Health Sciences (IRB-547/DUHS/Approval/2015/01).

\section{Consent:}

Signed consent was provided by the research team members, for the use of data collected through pre- and post-project questionnaires and focus groups, and through the Reflective Logs. The Ethical Review Committee agreed to an "opt-out" procedure, by which parents were able to withdraw their children from the project, because the research activities were deemed to be part of the educational activities offered by the school for the purpose of school improvement. No parents chose to withdraw their child from the project.

\section{Confidentiality:}

The names of children and schools are pseudonyms, with the exception of The AMI School, as it was the formal partner in the project.

\section{Conflict of Interest:}

The Authors declared no potential conflict of interest with respect to the research, authorship and publication of this article.

\section{Funding:}

The authors disclosed that this three-year (2015-2018) action research project was funded by the Knowledge Economy Partnership (KEP) funding from the British Council and Higher Education Commission of Pakistan. The three partner institutions were: the Occupational Therapy divisions at 
Brunel University London and Dow University of Health Sciences Karachi, and The AMI School, Karachi. The first author was a Lecturer in Occupational Therapy at Brunel University London for the duration of the project.

\section{Contributorship:}

Debbie Kramer-Roy was the Principal Investigator and provided leadership at all stages of this collaborative research study, from developing the funding proposal, to conducting the study, and reporting and preparing this publication. Denise Hashim and Nighat Tahir were the local Pakistani team leaders for the occupational therapists on the team, while Nasira Faiz and Rabeea Minai were the local team leaders for the teachers on the team. Areeba Khan, Asma Khalid, Samreen Jawaid, Shaheen Khan and Rakshanda Rashid constructed the data through the action research cycles in the classrooms, along with the team leaders. Tai Frater provided support to the research team at different times throughout the timeline, including the preparation of this manuscript. All Pakistani team members contributed to data analysis within the action research cycles (through the use of reflective logs), and workshops during field visits, including a final workshop to outline the article. Debbie Kramer-Roy drafted the initial outline, after which all co-authors provided examples and additional information, as well as critically reviewing each draft.

\section{References:}

Ainscow M and Miles S (2008) Making Education for All Inclusive: Where Next? Prospects 38:15-34.

Ainscow M and Sandill A (2010) Developing Inclusive Education Systems: the role of organizational cultures and leadership. International Journal of Inclusive Education 14(4): 401-416. DOI: 10.1080/13603110802504903.

Ardoin SP, Witt JC, Connel JE and Koenig JL (2005) Application of a Three-Tiered Response to Intervention Model for Instructional Planning, Decision Making, and the Identification of Children in Need of Services. Journal of Pscyho-educational Assessment 23(4): 362-380. DOI: 10.1177/073428290502300405.

Cahill C (2010) Participatory Data Analysis. In: Kindon, S, Pain, R and Kesby, M. Participatory Action Research Approaches and Methods. Connecting People, Participation and Place. Abingdon and New York: Routledge, pp.181-187.

Hameed A and Manzoor A (2016) Defeating inequalities in school access: a case of children with disabilities in Pakistan. Journal of Research in Special Educational Needs 16(s1): 345-350. DOI: 10.1111/1471-3802.12158.

Francis K (2013) Action Research. In: Taylor, B and Fancis K. Qualitative Research in the Health Sciences. Methodologies, Methods and Processes. London and New York: Routledge, pp.153-161.

Herbert CP, Bainbridge L, Bickford J, Baptiste S, Brajtman S, Dryden T, Hall P, Risdon C and Solomon P (2007) Factors that influence engagement in collaborative practice; How 8 health professionals became advocates. Canadian Family Physician 53: 318-1325.

Herr K and Anderson GL (2005). The Action Research Dissertation. A Guide for Students and Faculty. Thousand Oaks, London and New Delhi: Sage Publications. 
Kemmis S, McTaggart R and Retallick J (2004) The Action Research Planner. Karachi: Aga Khan University Institute for Educational Development.

Kennedy S and Stewart H (2011) Collaboration between occupational therapists and teachers: definitions, implementation and efficacy. Australian Occupational Therapy Journal 58: 209-214. DOI:10.1111/j.1440-1630.2011.00934.x.

Kramer-Roy D (ed) (2018) Inclusive Education in Pakistan: Resource Guide for Teachers and Occupational Therapists. Available: www.otiepakistan.pk

Law M, Cooper B, Strong S, Stuart D, Rigby P and Letts L (1996) The Person-Environment-Occupation Model: a transactive approach to occupational performance. Canadian Journal of Occupational Therapy 63(1): 219-234.

Letts L, (2003) Occupational Therapy and Participatory Research: A Partnership Worth Pursuing. The American Journal of Occupational Therapy, 57(1): 77-87.

Messiou K (2018) Collaborative action research: facilitating inclusion in schools. Educational Action Research. Online11.02.2018. DOI: 10.1080/09650792.2018.1436081.

Missiuna C, Pollock N, Levac D, Campbell SD, Whalen S, Bennet SM, Hecimovich B, Gaines R, Cairney $J$ and Russell DJ (2012) Partnering for Change: An Innovative School-Based Occupational Therapy Service Delivery Model for Children with Developmental Coordination Disorder. Canadian Journal of Occupational Therapy [online] (79: 41) available: http://cjo.sagepub.com/content/79/1/41.

Provincial Assembly of Sindh (2013) Sindh Right of Children to Free Compulsory Education Act. Available: http://www.pas.gov.pk/uploads/acts/Sindh\%20Act\%20No.XIV\%20of\%202013.pdf

Reeves S, Pelone F, Harrison R, Goldman J and Zwarenstein M (2017) Interprofessional collaboration to improve professional practice and healthcare outcomes. Cochrane Database of Systematic Reviews. Issue 6. Art. No.: CD000072. DOI: 10.1002/14651858.CD000072.pub3.

Sajid M, Hirani N, Umair B, Hameed S, Sohail M and Kramer-Roy D (in progress). The effectiveness of collaborative action research as a school improvement approach to develop inclusive education in a poorly resourced context.

Suter E, Arndt J, Arthur N, Parboosingh J, Taylor E, and Deutschlander S (2009) Role understanding and effective communication as core competencies for collaborative practice. Journal of interprofessional care 23(1): 41-51.

Trentham B and Cockburn L (2005) Participatory action research. Creating new knowledge and opportunities for occupational engagement. In: F. Kronenberg, S. Simo Algado \& N. Pollard, eds. Occupational Therapy without Borders. Learning from the Spirit of Survivors. Edinburgh: Elsevier, pp.440-453.

UNICEF (2017) The State of the World's Children: Children in a Digital World. Available at: https://www.unicef.org/sowc2017/ (accessed 30 October 2019).

UNICEF (2013) The State of the World's Children: Children with Disabilities. Available at: https://www.unicef.org/sowc2013/files/SWCR2013 ENG Lo res 24 Apr 2013.pdf (accessed 30 October 2019). 
UNESCO (1994) The Salamanca Statement on Special Needs Education. Available at: http://www.unesco.org/education/pdf/SALAMA E.PDF (accessed 30 October 2019).

UNESCO (1990) Word Declaration on Education for All. Available at:

https://unesdoc.unesco.org/ark:/48223/pf0000127583 (accessed 30 October 2019).

United Nations (1989) The Convention on the Right of the Child. Available:

https://www.ohchr.org/en/professionalinterest/pages/crc.aspx (accessed 30 October 2019).

United Nations Committee on the Rights of Persons with Disabilities (2016) General Comment No. 4.: Article 24, Right to Inclusive Education. Available: http://www.ohchr.org/Documents/HRBodies/CRPD/GC/RighttoEducation/CRPD-C-GC-4.doc (accessed 30 October 2019).

Villeneuve MA and Shulha LM (2012) Learning together for effective collaboration in school-based occupational therapy practice. Canadian Journal of Occupational Therapy 79: 293-302. DOI: 10.2182/cjot.2012.79.5.5.

Wintle J, Krupa T, Cramm H and DeLuca C (2017) A scoping review of the tensions in OT-teacher collaborations. Journal of Occupational Therapy, Schools and Early Intervention 10(4): $327-$

345. DOI: 10.1080/19411243.2017.1359134.

World Federation of Occupational Therapists (2018) Human Resources Project 2018. Available at: https://www.wfot.org/resources/2018-occupational-therapy-human-resources-project-editedalphabetical (accessed 30 October 2019).

World Federation of Occupational Therapists (2016) Position Statement on Occupational Therapy Services in School-Based Practice for Children and Youth. Available at:

https://www.wfot.org/resources/occupational-therapy-services-in-school-based-practice-forchildren-and-youth (accessed 30 October 2019). 


\section{Appendix:}

\section{Classroom Observation Log}

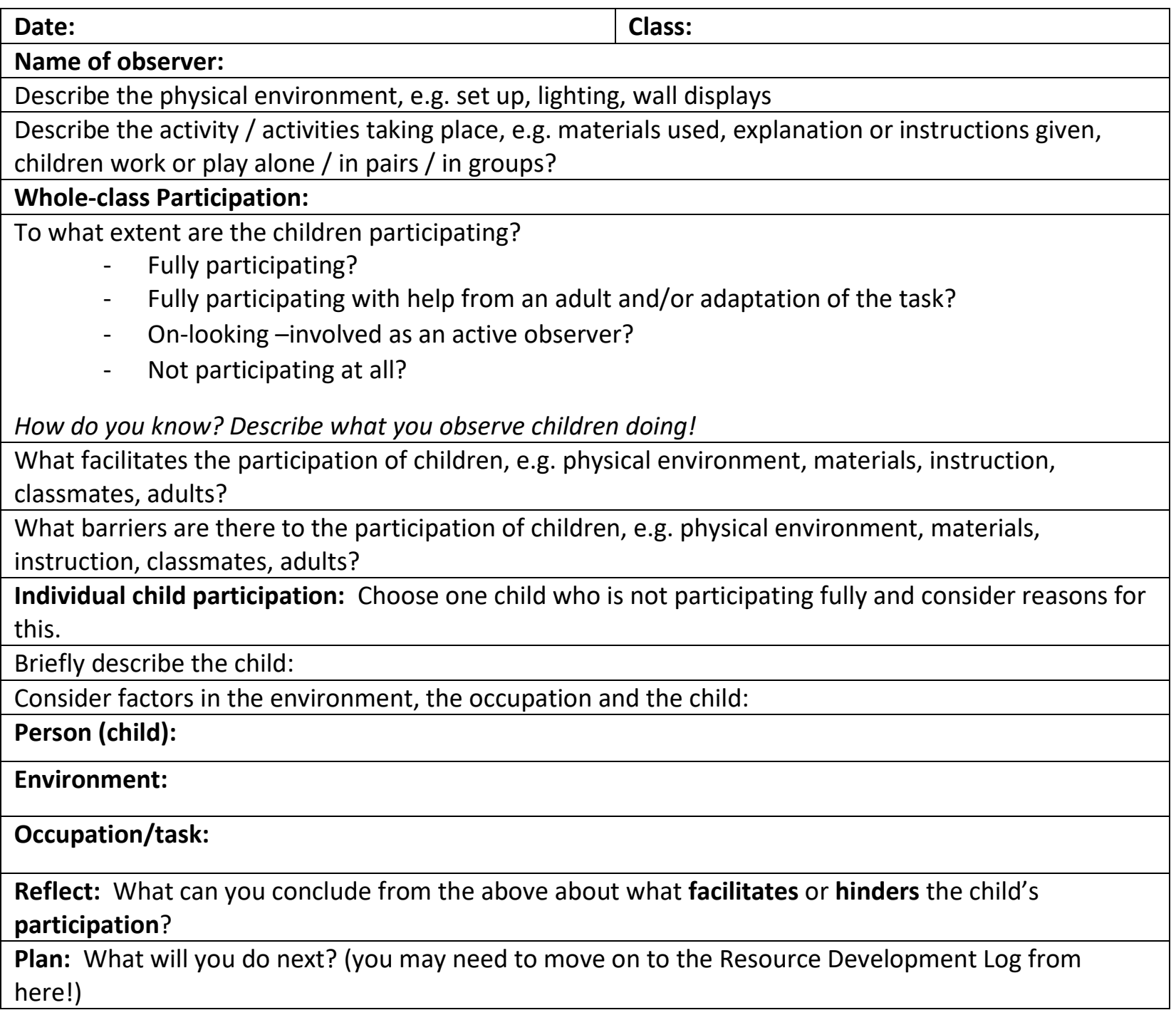

Log Sheet for Resource Development

(teaching materials, educational games, lesson plans, classroom strategies, etc)

\begin{tabular}{|l|l|l|}
\hline Date & Stage of Action Research cycle & What did I/we do? \\
\hline & $\begin{array}{l}\text { Identify Challenge: } \\
\text { What is the issue or challenge to be addressed? }\end{array}$ & \\
\hline $\begin{array}{l}\text { Explore: } \\
\text { Gain more info (e.g. from records / teachers / parents/ } \\
\text { OT assessment) }\end{array}$ & \\
\hline $\begin{array}{l}\text { Reflect: } \\
\text { What is the reason for the problem (use PEO) }\end{array}$ & \\
\hline $\begin{array}{l}\text { Plan: } \\
\text { Discuss options, list them and choose one }\end{array}$ & \\
\hline
\end{tabular}




\begin{tabular}{|l|l|l|}
\hline & Plan: \\
Think / read / explore www / use experience to design & \\
\hline & Act: & \\
Make the activity / thing / strategy / lesson plan & \\
\hline & Reflect: \\
Does it look like it will work? Any doubt? & \\
\hline $\begin{array}{l}\text { Act: } \\
\text { Make final adjustments }\end{array}$ & \\
\hline $\begin{array}{l}\text { Act: } \\
\text { Use it / apply it / try it out }\end{array}$ & \\
\hline $\begin{array}{l}\text { Observe: } \\
\text { Describe what you see when it is used }\end{array}$ & \\
\hline $\begin{array}{l}\text { Reflect: } \\
\text { How did it go and why? }\end{array}$ & \\
\hline $\begin{array}{l}\text { Plan: } \\
\text { Are any changes needed? }\end{array}$ & \\
\hline $\begin{array}{l}\text { Act: } \\
\text { Make adjustments OR Continue using it } \\
\text { AND File photograph / copy with this log with } \\
\text { instructions how to make it. }\end{array}$ & \\
\hline & Any other comments & \\
\hline
\end{tabular}

